\title{
General anaesthetics induce tonic inhibition and modulate the gain of neural populations : a modeling study
}

Axel Hutt, Thomas Voegtlin

From Twenty First Annual Computational Neuroscience Meeting: CNS*2012

Decatur, GA, USA. 21-26 July 2012

Anaesthetic agents are known to affect extra-synaptic GABAergic receptors[1], which induce tonic inhibitory currents. Since these receptors are very sensitive to small concentrations of agents, they are supposed to play an important role in the underlying neural mechanism of general anaesthesia. Moreover anaesthetic agents modulate the encephalographic activity (EEG) of patients and hence show an effect on neural populations. To understand better the tonic inhibition effect in single neurons on neural populations modulating the

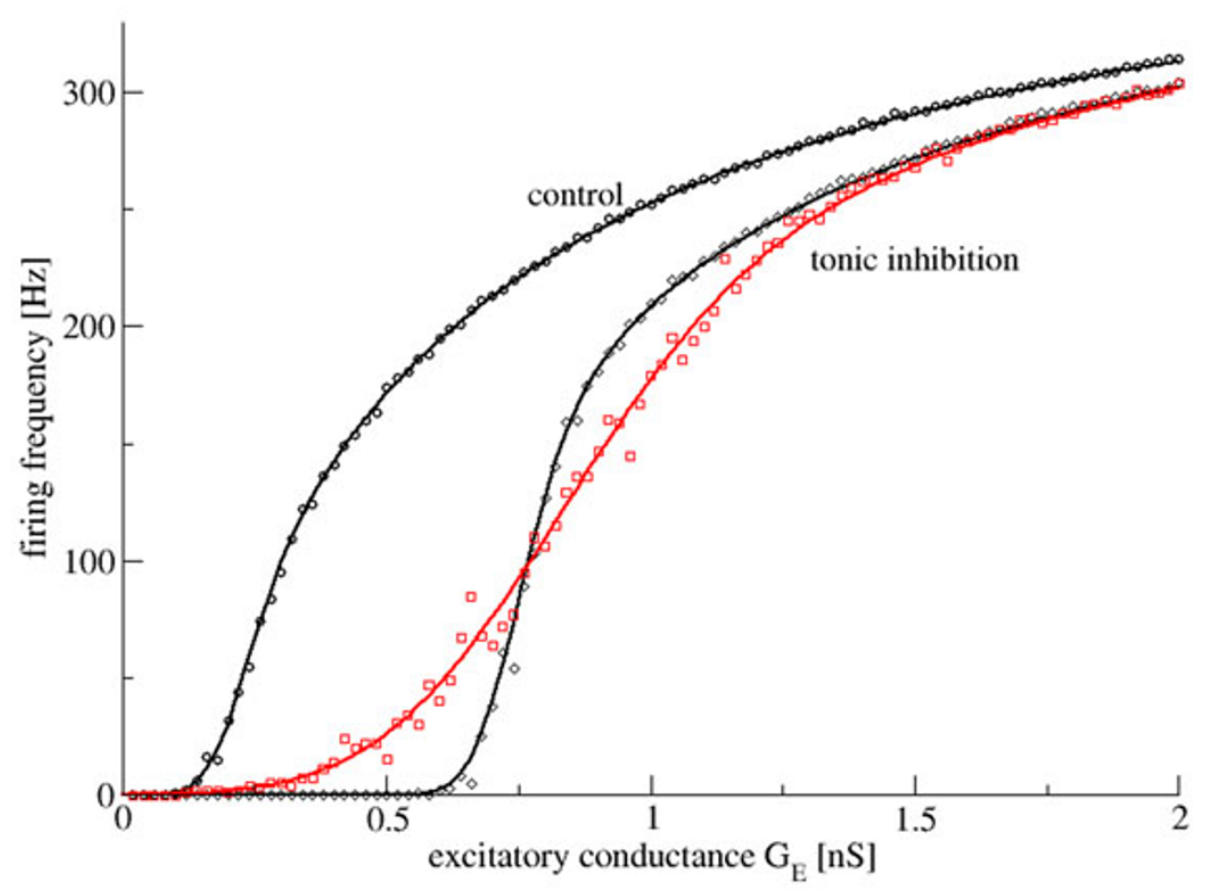

Figure 1 The population firing rate in a population of type-I neurons plotted with respect to the conductance at excitatory synapses $G_{E \text {. The }}$ tonic inhibition shunts the membrane at extra-synaptic inhibitory receptors in average by $0.1 \mathrm{nS}$. The heterogeneity of the shunting conductances have standard deviations $0.1 \mathrm{nS}$ (black) and 0.5nS (red).

* Correspondence: axel.hutt@inria.fr

INRIA CR Nancy - Grand Est, CS20101, 54603 Villers-Is-Nancy Cedex, France 
EEG, the work considers a neural population in a steady-state and studies numerically and analytically the modulation of its population firing rate and the nonlinear gain with respect to different levels of tonic inhibition. We consider populations of both type-I and type-II neurons. The populations under study are heterogeneous involving distributions of firing thresholds and inhibitory conductances. The tonic inhibition introduces shunting action.

The work reveals an increase of the population gain by increasing tonic inhibition and discovers a maximum of the gain subjected to the level of inhibitory heterogeneity, cf. Fig. 1 for a population of type-I neurons. Here we have implemented Integrate-and-Fire models including constant excitatory, inhibitory and leaky conductances. In addition to the numerical study, we derive analytical expressions for the population firing rate in the presence of the inhibitory heterogeneities. All numerical results show good accordance to the corresponding analytical expressions. The modeling results obtained show that tonic inhibition increases the firing threshold and augments the responsivenss of neural populations to external stimuli.

Summarizing, the present work has discovered an increase of the population firing threshold and a population gain modulation induced by tonic inhibition and presents a mathematical expression for the population firing rate. Since extra-synaptic receptors nduce tonic inhibition and are activated by several general anaesthetics, it is reasonable to reason that neural populations under anaesthetic action experience both effects. Consequently, we conclude that anaesthetics may both diminish the resting activity by shift of the firing threshold [2] and disrupts functionally neural circuits by increased population gain [3].

\section{Acknowledgements}

The research resulting to the presented work has received funding from the European Research Council under (FP7/2007- 2013) / ERC grant agreement $n$ 257253.

Published: 16 July 2012

\section{References}

1. Orser B: Extrasynaptic GABAA receptors are critical targets for sedativehypnotic drugs. J. Clin. Sleep Med 2006, 2:S12-8.

2. Steyn-Ross M, Steyn-Ross D, Sleigh J: Modelling general anaesthesia as a first-order phase transition in the cortex. Prog. Biophys. Molecul. Biol 2004, 85(2- 3):369-385.

3. Le Masson G, Renaud-Le Masson S, Debay D, Bal T: Feedback inhibition controls spike transfer in hybrid thalamic circuits. Nature 2002, 417:854-858.

doi:10.1186/1471-2202-13-S1-P16

Cite this article as: Hutt and Voegtlin: General anaesthetics induce tonic inhibition and modulate the gain of neural populations : a modeling study. BMC Neuroscience 2012 13(Suppl 1):P16.

\section{Submit your next manuscript to BioMed Central} and take full advantage of:

- Convenient online submission

- Thorough peer review

- No space constraints or color figure charges

- Immediate publication on acceptance

- Inclusion in PubMed, CAS, Scopus and Google Scholar

- Research which is freely available for redistribution 